\title{
Beyond Frameworks: Supporting Adult Educators to Leverage Technology and Customize the Learning Experience
}

Sarah Cacicio, Alison R. Shell, and Medha Tare, Digital Promise

Much like adult learners, adult educators enter the classroom with diverse educational, professional, and lived experiences-and varying levels of familiarity with digital tools and technology. But in the hours following the 2020 COVID-19 outbreak and subsequent shutdown, educators across the nation were suddenly tasked with teaching online. For the most part, educators in adult literacy, academic, and ESOL programs had limited experience with online learning prior to the crisis (World Education, 2020). As Vanek describes in her forum piece, Supporting Quality Instruction: Building Teacher Capacity as Instructional Designers, the majority of educators had to quickly learn and adopt new ways of planning and delivering instruction. Over time, the conversation around the role of technology in adult education shifted. In spite of the tremendous hardship experienced in and outside of the classroom, the crisis revealed an untapped opportunity to meet the needs of adult learners more effectively through flexible programming, digital skills development, and personalization of learning. Vanek indicates that online learning may be "a previously under-utilized but promising” instructional option in adult education. To better leverage technology across the field, the author suggests that educators adopt clear models or frameworks to effectively design instruction, make informed decisions about digital tools and platforms, and ultimately, meet the complex and varied needs of adult learners.

But how can we meaningfully integrate technology into adult education without fully acknowledging the backstories, emotions, and skills of the learners and educators who serve them? While Vanek acknowledges that different frameworks resonate well with different teachers, depending on their planning style, comfort, and past experience, the underlying factors that may influence decision-making are not adequately explored. The purpose of this article is to delve deeper into the myriad individual and systemic factors that impact the adult learner, educator, and their interactions through the lens of learner variability. Embracing well-designed and implemented education technology is a major step in the future of equitable and sustainable learning for adult education, and understanding the whole person remains at the core of learner success.

\section{Understanding Learner Variability}

Learner variability is the recognition that all students differ, and that learning sciences research guides us in understanding how these differences matter for learning (Pape, 2018). 
Research is clear that adult learners, much like their younger counterparts, vary greatly in terms of their cognitive abilities, social and emotional considerations, and unique background situations (Tare et al., 2020). Adult learners are motivated to improve their education and career outcomes, but to successfully pursue pathways that lead to greater social mobility, they also need affordable childcare, stable housing, access to high quality healthcare, and livable wages (Simpson-Baird, 2020). When background factors such as these are considered together, along with contentspecific factors, adult educators can better identify what each learner requires to realize their goals. Educators who adopt a whole learner framework can build stronger relationships with their students, create more meaningful learning experiences, and promote better outcomes. This process includes strengthening culturally responsive teaching by incorporating students' identities and real-world issues into learning environments and instructional practices (Harrison, 2021).

Digital Promise's Adult Learner Model, created by the Learner Variability Project (LVP), synthesizes learning sciences research across four key areas of adult learning-literacies, cognition, socialemotional, and learner background. It explains how factors such as digital literacy, working memory, motivation, and adverse experiences impact learning, and critically how these factors interact with each other. For example, research shows that having greater self-efficacy for using computers can reduce the amount of anxiety adults feel about technology use-anxiety that may have arisen from prior negative experiences with schooling (Saadé \& Kira, 2009). As such, we may better be able to target the root of a challenge which may have broader and longer-lasting impact. For instance, addressing this learner mindset to promote efficacy in technology use, as well as its origins (e.g., lack of social support, stereotypes based on their identity) may increase persistence in learning these skills and ultimately, improved performance.

\section{LVP's Adult Learner Model curates instructional} strategies that span active learning, collaboration, multisensory, and metacognitive support to promote the development of high-quality, personalized learning experiences that address the needs of the whole learner. Taking a whole learner approach is critical to advancing highquality, technology-rich instruction to improve adult learner outcomes across the field, but to do this effectively, we must consider the realities that impact instructional decision-making and activities beyond models or frameworks. The following section takes a closer look at some of the underlying and systemic challenges that often affect teacher-student interactions in adult education, such as a majority part-time staff, a lack of racially diverse teachers, and mixed expectations for online learning.

\section{Factors that Impact the Adult Education Workforce}

\section{Majority Part-Time Staff}

In the wake of the pandemic, the ability for adult educators to understand and adjust to the realities of students has become even more of a necessity (Simpson Baird, 2020). Adult educators are committed to this work, but it is well documented that instructors often struggle to meet the complex needs of the adult learner population due to limited time and resources. Adult educators work across a variety of learning environments, from school districts, adult charter schools, and community colleges to workforce training programs, library programs, and correctional or re-entry facilities-each with its 
own instructional design and access challenges. Educators recognize that planning and delivering high-quality, technology-enabled instruction also requires addressing inequities related to internet connectivity, access to appropriate devices, family and job responsibilities, and health and safety (Means \& Neisler, 2020). Despite the growing need for investment in adult education and training, the profession continues to rely heavily on part-time instructors and volunteers, including retired $\mathrm{K}-12$ teachers, often with little to no defined training or support (Harrison, 2021). Approximately $78 \%$ of adult educators funded under the federal Workforce Innovation and Opportunity Act (WIOA) are employed part-time, providing instruction for more than 1.4 million learners through adult literacy, high school equivalency, and English language programs annually (BergsonShilcock, 2020). While part-time educators are wholly invested in their students, they may not have the time, training, or resources to adequately leverage technology integration frameworks in ways that support the whole learner. Further, research shows that there is often a cultural, racial, and socioeconomic disconnect between the adult learner population and the administrators and educators who serve them.

\section{Educator Background}

The U.S. population is expected to be minority white by 2045 , but as U.S. demographics continue to shift toward a more racially diverse population, the number of $\mathrm{K}-12$ teachers of color has not kept pace (Digital Promise, 2020). This same trend is reflected in adult education. While adult learners are predominantly young, Black, Latino, and/ or immigrant-origin people who are seeking socioeconomic mobility, administrators and teachers in the adult education field remain overwhelmingly white, often older and/or retired, and from high socioeconomic statuses
(Harrison, 2021). Research in $\mathrm{K}-12$ education shows significant benefits to increasing a diverse educator workforce, with more teachers reflecting the identities and experiences of their students. Teachers who share a similar background to their students have been shown to have more empathetic understanding of student perspectives, higher expectations for academic performance, and improved student engagement (Digital Promise, 2020; Egalite \& Kisida, 2018). This is not to say that teachers with different racial, socioeconomic, cultural, or linguistic backgrounds are not able to build meaningful connections or effectively apply culturally relevant teaching practices. Rather, teachers whose identities reflect student populations are more likely to already see their students as capable of knowing their own needs, able to be self-guided, and interested in events that impact their dayto-day lives (Harrison, 2021). When students feel known, accepted, and supported in their learning environment, they have the sense of belonging they need to take risks and work through challenges that allow for engaging and productive learning. In her groundbreaking piece, A Diversity Call to Action for Adult Education, Harrison (2021) makes clear the need for educators to support their students' racial and cultural identities "so that they can go into the workforce and further schooling as their whole selves." Today, teachers must also help cultivate and support adult learners' digital identities to better prepare them for success in education, work, and life.

\section{Educator Mindset}

Research shows that teacher expectations of student success matter and can become a selffulfilling prophecy by promoting or impeding success according to their expectations (Papageorge et al., 2020). Further, teachers' success in promoting a growth mindset in their 
learners is heavily tied to their own growth mindset (Yeager et al., in press). Not only do learners need to be engaged and confident to be successful learners, but educators need to believe in themselves, and their students. Adult educators, much like learners, are more engaged and motivated when learning experiences offer them ownership of their learning, as well as prioritize immediacy of application, selfdirection, and sharing of life experiences as a source of knowledge. Prior to the pandemic, most adult education courses took place in-person across a variety of learning contexts. Many states reported that adult education staff needed convincing that all learners could be successful in a virtual learning environment. Supporting teachers in shifting mindsets through high quality professional learning is crucial to shifting effective practices online and promoting student achievement (World Education, 2020).

\section{Applying Technology Integration Frameworks with a Whole Learner Approach}

When it comes to professional development for technology-rich instruction, a blend of selfdirected frameworks and facilitated training through a whole learner approach can provide opportunities for educators to grow their own digital skills and reflect on how they can best serve their students. Vanek encourages adult educators to leverage frameworks and strategies to make more efficient and sound decisions about digital resources and technology integration. One of her recommendations includes the Triple E Framework created by Professor Liz Kolb, which suggests that digital tech should engage, enhance, and extend learning goals (Kolb, 202O). Dr. Kolb recommends using this framework for evaluating digital strategies and reflecting on technology in conjunction with the Learner Variability Project's whole learner models. In this way, educators are taught to identify and consider the particular factors that are relevant for their learners and to seek research-based strategies that would support them individually. Once this understanding is in place, technology decisions are made based on which tools can best provide the support needed by different diverse learners. This approach can also help to fill gaps in educators' knowledge of adult learning theories such that they understand why particular technologies may be beneficial, supporting their use of technology for diverse learners more broadly. Building adult educator capacity in technology use is absolutely vital to the advancement of learners.

\section{The Promise of Digital Learning in Adult Education}

Adult learners have differing abilities and experiences with technology, but they are deeply motivated to continue their education and expand their digital skills. Research reveals that adult learners have already shown a mindset shift when it comes to using technology to advance their education and career goals. In May 2020, Simpson Baird and a team of researchers conducted a survey of more than 1,800 adult learners across seven adult charter schools in Washington D.C. to learn how the pandemic was impacting them. At the time, an overwhelming majority of adult learners-more than $92 \%$ people of color, including over 50\% English learners-expressed challenges with technology and a preference for in-person learning. In December 2020, the team administered a follow-up survey to determine how learners were faring after several months of virtual learning. Compared to spring 2020, the majority of the approximately 1,500 respondents enrolled in fall 2020 indicated higher levels of competence 
with technology, more confidence in supporting their children's education, and higher levels of employment (Simpson Baird et al., 2021). Overall, adult learners also expressed a greater appreciation for the increased flexibility that virtual learning provides, such as eliminating a commute, being able to learn from anywhere there is Wi-Fi, and not needing to secure childcare to study (Simpson Baird et al., 2021). As Simpson Baird (2020) poignantly notes, for many adult learners, "their futures as well as the economic livelihoods of their families are contingent upon learning English, finishing high school, or gaining a credential; they do not want to put any of this on hold because of the pandemic" (para. 12). While this is a small sample of adult learners, these findings support what Vanek suggests: that distance education may be a powerful and promising option for the adult education field moving forward.

Understanding student realities goes beyond gauging access to devices and broadband internet or surveying skills and interests.
Adult educators must also take into account multiple factors related to literacy, cognition, social-emotional, and learner background, in addition to how their own experiences can impact their students' learning. Vanek and colleagues at World Education's EdTech Center offer a learner-centered protocol for decisionmaking, encouraging teachers to explore the "what," "why," and "how" of strategies to ensure that technology is integrated purposefully to meet learner needs, and we recommend contextualizing this protocol to even more deliberately consider the "who." Through the lens of learner variability, educators will be able to make more informed decisions about technology integration and expand equitable access to high quality education and training for adult learners. When educators have the background knowledge, mindset, capacity, and support they need to truly understand their learners, they can more confidently select and implement edtech tools and strategies to create meaningful relationships and learning experiences. 


\section{References}

Bergson-Shilcock, A. (2020). The new landscape of digital literacy: How workers' uneven digital skills affect economic mobility and business competitiveness, and what policymakers can do about it. National Skills Coalition. https://www. nationalskillscoalition.org/resources/publications/ file/New-DigitalLandscape-web.pdf

Digital Promise (2020). Pipeline and retention of teachers of color: Systems and structures impeding growth and sustainability in the United States. https://digitalpromise. org/wp-content/uploads/2020/o4/Teacher-of-ColorLit-Rev-Rpt_FINAL.pdf

Egalite, A. J., \& Kisida, B. (2018). The effects of teacher match on students' academic perceptions and attitudes. Educational Evaluation and Policy Analysis, 40(1), 59-81. https://doi.org/10.3102/0162373717714056

Harrison, D. (2021). Let us teach to us: A diversity call to action for adult education. COABE Journal, 9(2), 42-47.

Kolb, L. (2020). Keynote: The triple E framework: Using researchbased strategies for technology integration. SITE-Society for Information Technology \& Teacher Education International Conference. Association for the Advancement of Computing in Education.

Means, B., \& Neisler, J., with Langer Research Associates. (2020). Suddenly online: A national Survey of undergraduates during the COVID-19 pandemic. Digital Promise. https://digitalpromise.org/wp-content/ uploads/2020/07/ELE_CoBrand_DP_FINAL_3.pdf

Pape, B. (2018). Learner variability is the rule, not the exception. Digital Promise. https://digitalpromise.org/wpcontent/uploads/2018/o6/Learner-Variability-Is-TheRule.pdf

Papageorge, N. W. , Gershenson, S., \& Kang, K. M. (2020). Teacher expectations matter. Review of Economics and Statistics, 102(2), 234-251. https://doi. org/10.1162/rest_a_00838
Saadé, R. G., \& Kira, D. (2009). Computer anxiety in e-learning: The effect of computer self-efficacy. Journal of Information Technology Education: Research, 8(1), 177-191. https://doi.org/10.28945/3386

Simpson Baird, A. (2020). The impact of COVID-19 on D.C.'s adult learners: Results from a spring 2020 survey. D.C. Policy Center. https://www. dcpolicycenter.org/publications/covid-adultlearners-survey/

Simpson Baird, A., Fragale, J., \& Smith, D. (2021). D.C.'s adult learners during the pandemic: Results from a Fall 2020 survey. D.C. Policy Center. https://www. dcpolicycenter.org/publications/adult-learnerspandemic-survey/

Tare, M., Cacicio, S., \& Shell, A.R. (2020). The science of adult learning: Understanding the whole learner. Digital Promise. https://digitalpromise.org/wp-content/ uploads/2020/12/Adult-Learner-White-Paper-1.pdf

World Education. (2020). What we learned: Adult education's response to emergency remote teaching and learning. https://edtech.worlded.org/wpcontent/uploads/2020/o7/WEI-for-BMGF-Adult-EdCOVID19-Response-8.2020.pdf

Yeager, D. S., Carroll, J. M., Buontempo, J., Cimpian, A., Woody, S., Crosnoe, R., Muller, C., Murray, J., Mhatre, P. , Kersting, N., Hulleman, C., Kudym, M., Murphy, M., Duckworth, A., Walton, G. M., \& Dweck, C. S. (in press). Teacher mindsets help explain where a growth mindset intervention does and doesn't work. 